\title{
Unique opportunities: Influence of study abroad on Black students
}

\author{
Jasmine Lee and Qiana Green \\ Michigan State University
}

The National Survey of Student Engagement (NSSE) (2007) Institute for Effective Educational Practice outlines study abroad as a High Impact Practice (HIP) (Kuh, Kinzie, Schuh, \& Whitt, 2010). HIPs are educational experiences that make a significant difference to student persistence, learning outcomes, and student success (NSSE, 2007; Kuh et al., 2010). As such, participation in study abroad is positively associated with persistence and GPA, HIP approaches to learning, higher rates of student-faculty interaction, increases in critical thinking and writing skills, greater appreciation for diversity and deeper student engagement overall (Brownell \& Swaner, 2009; NSSE, 2007; Kuh, 2008; Kuh et al., 2010). Despite the positive outcomes associated with study abroad experiences, Black students continue to be underrepresented among participants, comprising only about five percent of US students who studied abroad in the 2012-2013 academic year (NAFSA, 2015).

Not only is the percentage of Black study abroad participants low, the percentage of US students who traveled to the African continent is also low. According to the same study, only 5\% of the total US students who studied abroad traveled to the continent of Africa (NAFSA, 2015). Few studies have examined Black students' participation in study abroad and even fewer have examined their experiences studying abroad in Africa (Brown, 2002; Dawson, 2000; Penn \& Tanner, 2009; Tolliver, 2000; Walker, Bukenya, \& Thomas, 2011). This research adds to the dearth of literature examining the experiences of Black students who study abroad. Additionally, this project extends the literature on the influence of diasporic travel on US Black undergraduate students.

Because study abroad has positive benefits for student learning and development (Brux \& Fry, 2010), targeted study abroad opportunities could be used as a vehicle for retention and engagement for Black undergraduates. The current study explores the experiences of four Black undergraduate students who studied abroad in South Africa. Authors examined how this particular study abroad experience to South Africa influenced Black undergraduate students' understanding of their Black identity, and increased their knowledge of South Africa and South Africans through collaborating with the community.

In the following sections of this article, we briefly discuss the theoretical framework, methodology, and findings, along with implications for future research and practice.

\section{Literature Review}

Purpose of study abroad in the US

Study abroad continues to increase in the United States, rising from 68,000 participants in the $1987 / 1988$ academic year to 289,408 in 2012/2013 (IIE, 2013). Study abroad has increased due to students' desire to engage with and prepare to work with people from all over the world (NAFSA, 2003). Study abroad provides participants opportunities to interact with people from different 
cultures, thus allowing participants to learn how to live and work with people from different backgrounds in ways that lead to the consideration of our global issues (Nolan, 2009). The following section discusses Black students' participation in study abroad, highlighting participation numbers, experiences, and benefits to them.

\section{Barriers to Black student participation}

Black students not only participate in study abroad in low numbers, but are also underrepresented in higher education enrollment as a whole. Black students comprised $14.9 \%$ of the total students enrolled in US postsecondary institutions in 2012/2013 and as mentioned earlier represented 5.3\% of students who studied abroad during the 2012/2013 academic year (IIE, 2013). Examining Black students' underrepresentation in study abroad may lead future researchers to understanding larger systemic issues regarding Black students low participation in higher education as a whole.

Knowing that study abroad is a HIP, one must consider reasons why Black students participate in study abroad in such low numbers. Black students are underrepresented in study abroad participation for a variety of reasons. Due to habitus or "previous experiences which can impose unconscious limits on an individual's educational and career aspirations" (Gasman, Baez, \& Turner, 2008, p. 221), students of color in particular may not seek out, get involved in, and/or pass up activities, including studying abroad, during their college career. This often manifests later in life and impacts motivation to pursue activities, like study abroad, during their undergraduate degree.

In the case of study abroad, students of color often do not feel this is an activity for them (Brown, 2002; Penn \& Tanner, 2009; Walker et al., 2011), which results in their missing out on the benefits. Additionally, lack of knowledge regarding funding and worries about graduating on time often inhibit Black students from studying abroad (Cheppel, 2012; Jackson, 2006; Kasravi, 2009; Willis, 2012). Further, students are highly influenced by friends, classmates, and parents (Walker et al., 2011). Thus, for Black students, funding, academic obligations, and if one does not know other Black students or family who have studied abroad, they are less likely to study abroad themselves.

\section{Challenges to studying abroad to African countries}

There are some additional challenges for Black students when studying abroad in African countries. Common challenges include misunderstandings around race and racism in African contexts (Gearhart, 2005), facing stereotypes based on nationality (Day-Vines, Baker, and Exhum, 1998; Landau \& Moore, 2001), and assumptions of fit (Gearhart, 2005). Often, Black students' understandings of race and racism is informed by their experiences in the United States (Gearhart, 2005). While very real, these American experiences with race and racism differ greatly from such experiences in African countries. Some students may be challenged by how these varying experiences of race and racism shape their time studying abroad in African countries.

Stereotypes about Americans also serve as a challenge. Some African American students are surprised by how they are stereotyped based on their national identity (Day-Vines, Baker, and Exhum, 1998; Landau \& Moore, 2001). Black American students who travel to African countries often find themselves being confronted for the first time about being American (Day-Vines et al., 1998; Landau \& Moore, 2001). This might differ from their experiences in the United States where 
being Black is often their most salient identity (Jackson, 2006). Additionally, some American Black students assume they will be able to fit or blend into communities in African countries (Gearhart, 2005). Students with unrealistic expectations of fitting in are often disappointed when it is clear to others they are not from the given country or area (Gearhart, 2005). On the other hand, some students who do have experiences of fitting in may feel stuck when someone begins speaking to them in a language they do not know. Particular experiences of visually fitting in, but not knowing the language or cultural norms, can leave students potentially feeling awkward and embarrassed (Gearhart, 2005).

\section{Benefits of studying abroad in Africa}

Studying abroad in countries along the African diaspora often provide Black students' opportunities to discuss issues of race and racism (Tolliver, 2000) and explore their heritage (Brux \& Fry, 2010). The few Black students who do participate stated their study abroad experiences provided them with opportunities to gain cross-cultural learning and connection to ancestors as well as exposure to other cultures (Dawson, 2000; Tolliver, 2000).

Black students who study abroad to the continent of Africa with other Black students gain multiple shared benefits and rewards from their study abroad experience in Africa. For example, many report gaining a deeper understanding of self (Penn \& Tanner, 2009; Tolliver, 2000) and are able to experience the surroundings with other Black students (Dawson, 2000). Shared historical roots allow students to connect with their ancestors and imagine what it must have been like, as an African, to be captured, enslaved, and to walk through the "door of no return" (Dawson, 2000, p. 127). Through this home going experience, African American students may feel more equipped to answer questions about who they are and where they came from (Dawson, 2000; Penn \& Tanner, 2009). Learning about African culture assists Black students in understanding themselves spiritually and historically (Penn \& Tanner, 2009).

Students express feeling blessed for all they have been given while on study abroad trips to Africa. Being exposed to new physical environments (i.e. airports, nature, city infrastructure, the structure of people's homes; Dawson, 2000) opens African American students' eyes to the fact that there are multiple ways of living. Additionally, noticing the lack of access to water and not being able to just go to a store whenever they wanted (Dawson, 2000), results in feelings of "gratefulness, tolerance, and patience" (Dawson, 2000, p. 127) for Black students. Understanding that all experiences in Africa will not be the same (e.g. all students will not experience small tribal communities with no access to water), being exposed to multiple ways of living broadly, and seeing through a new lens, positively impacted these students lives and contributes to their personal growth. These experiences may be common for all study abroad students, however given the lack of research on Black study abroad participants, we intentionally chose to highlight research focusing on Black participant experiences.

Because of the (mis)education of Black students (See Woodson, 1933) in formal schooling, many African American students "do not always understand their relationship to Africa" (Dawson, 2000, p.125). Along with misinformation taught during formal education in the United States, Black students may also receive incorrect information about Africa in the media (Dawson, 2000). This misinformation may influence their perceptions and therefore their participation in study abroad 
programs to the African continent. Negative images of Africa and Africans portrayed in the media all act as hindrances not only for Black students to study abroad, but specifically to studying abroad in Africa (Dawson, 2000; Landau \& Moore, 2001). Many students have bought into the media's portrayal of Africans and are also concerned about how they will be perceived by Africans; both are concerns that hinder and challenge their participation in these programs (Dawson, 2000).

In the following section, the authors discuss the theoretical framework at the foundation of this study.

\section{Theoretical Framework}

The current study is situated within the Afrocentric Paradigm, with Afrocentricity as its theoretical framework. Afrocentricity creates a context, centering the experiences of Blacks along the African diaspora in a way that intertwines cultural, spiritual and experiential knowledge. Afrocentricity operates under a broader paradigm that is a philosophical and theoretical construct within Pan-African studies (Mazama, 2003). The primary basis of Afrocentricity is the epistemological centeredness of the experiences of Africans (Mazama, 2003). Within the current research, we consider African(s) to include self-identified Blacks with African heritage who are found within the diaspora. Asante (1987) defines "Afrocentricity as a theoretical framework to be used to examine and self-consciously advance African people in every sector of society" (p. 37). Reviere (2001) further states, "Afrocentric methodologies are to be used to investigate important research questions legitimately and effectively, particularly those that possess embedded assumptions about race and culture" (p. 709). Utilization of the Afrocentric paradigm is useful in the current case study due to the focus on students of the African diaspora, studying African culture, in an African context.

Afrocentricity is holistic in nature, considering both spiritual and cultural experiences, in addition to inquiry, which allows us to fully consider the ways in which this program and the associated experiences influenced participating students. Further, within Afrocentricity there is a commitment to the creation of knowledge as liberation (Mazama, 2003). Thus, we situate this work within the broader study abroad literature in a way that creates considerations for the benefits of study abroad, particularly to the continent of Africa, and for Black students.

Rooted in the basic premises of Afrocentricity (Mazama, 2003), the current study (1) specifically focuses on the perspectives of Black students of African descent, paying particular attention to their experiences on a South African study abroad experience; (2) centers viewpoints and stories of Black participants; and (3) understands, and reinforces, the usefulness of the Black experience to explore the broader needs of students across races. Within this conceptual framework the current study was conducted and the following analysis is presented.

\section{Methods}

The current study is a qualitative analysis utilizing case study methodology. Within case study research, a "case" can be an individual person, a group of people, or a decision (Glesne \& Peshkin, 2011; Yin, 2008). The Research in the New South Africa (SARP) study abroad trip serves as the case considered within the current study. As authors sought to investigate study abroad experiences within real-life contexts, and sought to answer "how?" and "why?" questions (Yin, 2008), case study 
methodology proved to be most useful. Case study allowed us to explore and understand contemporary, complex social phenomena around study abroad experiences for underrepresented students, particularly those who identify as Black. Case study does not provide data that is largely generalizable to multiple populations (Yin, 2008), but does provide rich data with deep understanding into participant experiences. Because of the focus on exploratory research (Yin, 2008), case study is suitable as we explore the ways study abroad to the African continent influences Black college students.

The current qualitative study utilized one-on-one semi-structured interviews to better understand how a study abroad trip to South Africa influences these four Black undergraduate students. Such interviews aim to facilitate a conversation eliciting rich stories and allowing for flexibility, while generating detailed accounts as opposed to brief answers or general statements (Esterberg, 2002; Patton, 2002). Semi-structured interviews were particularly useful to co-construct meaning with participants around their study abroad experience, allowing interviewees to express their opinions and ideas in their own words (Esterberg, 2002). Interviews focused on questions regarding student experiences and behaviors, opinions and values, feelings and personal background (Patton, 1990), all in relation to their study abroad experience with SARP, and were conducted by the lead author. Interview questions were asked to understand the influence of this particular study abroad on Black students, with a particular focus on academics, undergraduate research, and racial identity, which were structural components of the program. Questions were developed to explore how participation in SARP encouraged students to think about their long-term academic plans and how they understood themselves within the African Diaspora. Further, given the research focus of the program, some questions were asked to explore ways SARP influenced participants' ability to conduct research.

\section{Program Description}

In an attempt to combat the underrepresentation of Black students in study abroad, some institutions are designing more targeted experiences to attract Black students to study abroad. Programs like SARP are combining educational research with community engagement, while studying abroad to South Africa. More specifically, students interact with the local Black community through interactions with school children, community organizers, and families.

In this targeted study abroad experience, senior undergraduate and doctoral participants spent three weeks in South Africa, and engaged in a two-week internship, required field research, and collaborative study. Because this study abroad program was to South Africa and was administered through the Africana Studies Department, this research pays particular attention to the experiences had by participants as Black individuals in an African context. Based on participant experiences, this research attempts to connect the literature on HIPs of study abroad to its positive impact on the Black participants within this study.

The first SARP trip was held in 2013 and is housed within the Africana Studies Department. The program was intentionally developed to respond to the need for more diverse student participation in study abroad and more intentional design for programs on the African continent. In particular, SARP serves as an opportunity for underrepresented students to study abroad. Students are recruited to participate in the program via various traditional study abroad marketing methods 
used at the institution, but also through targeted marketing toward participants taking courses in or with related interest in Africana studies.

SARP was 25 days long and included academic, cultural, spiritual, social, and internship components. SARP integrated advanced undergraduate students (seniors) with graduate level students (doctoral students). However, the focus of the current analysis is on the experiences of the undergraduate participants. Interaction between undergraduate and graduate students allowed for a deep learning experience for all participants involved. The structure of the study abroad program was intentional in avoiding stereotypical experiences while visiting the African continent such as safaris, and instead focused on creating a connection with the history, cultures, and people of South Africa. This study abroad program was offered at a large predominantly White, midwestern university and takes place primarily in Pretoria, South Africa. Further, students spent time at two universities in South Africa.

There were multiple components to the structure of the program. First, participants conducted individually planned and executed field research projects, including one-on-one interviews, focus groups and data analysis. In addition to research-oriented work and associated academic readings, participants also engaged in intensive language training (isiZulu and Venda). Third, participants took part in an internship with a local research organization or international African k-12 academy. Participants served as research assistants with professors; or taught English, history, or creative writing to elementary and middle school aged children. Outside of the academic focus, participants engaged in a variety of cultural, social, and spiritual activities, including a retreat to Mapungubwe (world heritage site of the oldest known remains in Southern Africa), Thabo Mbeki Lecture, Nelson Mandela Museum, Sangoma ceremony in Soweto, and various other museums, and lectures.

\section{Participants}

In accordance with qualitative research and case study methodology, this study used a purposeful sampling strategy (Creswell, 2007; Patton, 2002). When using purposeful sampling, the researcher outlines specific criteria that the participants must fulfill, allowing for selection of participants (Creswell, 2007). Being clear about the criteria used for selection of participants allows for transferability in future contexts, as is the goal of qualitative research study. For the purposes of this study the criteria we used is as follows:

- Self identify as Black or African American

- Undergraduate participant in SARP

- The criteria was left purposely vague in order to allow for the greatest number of participants.

Four undergraduate students participated in the South Africa study abroad trip and all four were interviewed for this research study. Interview participants were all undergraduate students from a large, midwestern, research-intensive institution. Below is a brief description of participants and their accompanying pseudonym. All participants sought to attend SARP due to their interest in Black history, politics and "liberation". Lastly, two of the four had never traveled abroad prior to this experience. 
Table 1. Participant characteristics

\begin{tabular}{|c|c|c|c|c|c|c|}
\hline Pseudonym & Age & Race & Gender & Class level & Major & Minor \\
\hline Ahmad & 20 & Black & Male & Senior & Journalism/ Film & N/A \\
\hline Michelle & 20 & $\begin{array}{l}\text { Congolese/ } \\
\text { Black }\end{array}$ & Female & Senior & $\begin{array}{l}\text { Comparative } \\
\text { Cultures \& } \\
\text { Politics }\end{array}$ & $\begin{array}{l}\text { African } \\
\text { American \& } \\
\text { African Studies }\end{array}$ \\
\hline Brittany & 21 & Black & Female & Senior & History & $\begin{array}{l}\text { Urban } \\
\text { Education }\end{array}$ \\
\hline Tonya & 21 & Black & Female & Senior & Political Science & N/A \\
\hline
\end{tabular}

\section{Data collection and analysis}

Both authors were engaged in the data analysis of this research study at different stages. One on one semi-structured interviews were conducted once participants returned from South Africa and had about two weeks to reflect on the experience. Interviews ranged from one to two hours, and were conducted and digitally recorded by the lead author. Both authors transcribed the interviews and conducted analytical read-throughs (Miles \& Huberman, 1994) of interview transcripts. Readthroughs and coding were initially completed individually and then a second time together in order to talk through any disagreements of the data and meaning interpreted. Open/axial coding (Charmaz, 2006) was used to interpret the data and generate themes. Each individual case was reviewed and analyzed to give individual meaning. Individual themes were then combined to generate broad themes represented by all transcripts.

\section{Trustworthiness}

Trustworthiness is a means through which a researcher evaluates whether their claims are sufficiently supported by evidence (Hammersley, 2008). As researchers, our aim is to understand the meanings participants attached to specific events during their participation in SARP (Polkinghorne, 2007). There are multiple methods we employed to ensure the trustworthiness of the current study. First, the semi-structured and in-depth method itself allowed for a co-constructed meaning making process, within which the interview participants guided the conversation. In-depth interviews are intensive one-on-one conversations with small numbers of participants. In addition to the interviews, we engaged in member checking (Chase, 2005; Patton, 2002) as a source of trustworthiness.

Member checking is when narrative researchers return to the narrators to "inform them, and ask again for permission to use their stories" (Chase, 2011, p. 424). We collected and analyzed data, and presented findings to participants in order to ensure we captured their thoughts, feelings, and experiences correctly. We made adjustments as needed. Additionally, we maintained shared analytic memos, procedural memos, and reflective journals for the entirety of the research process (Esterberg, 2002). Lastly, we ensured trustworthiness as co-researchers by peer debriefing, which is the process of peer review or debriefing by a colleague familiar with the research or phenomenon being explored (Creswell \& Miller, 2000). In congruence with Lincoln and Guba (1985) we engaged 
in a process wherein we challenged assumptions, methods, and interpretations to generate our final findings.

\section{Researcher Positionality}

Moving diverse individuals from the margins to the center of discourses, programs, interventions, and theories may create campuses in which everyone feels validated for their differences (hooks, 1984); within this phrase this piece and our broader work finds its meaning. To better understand the lens through which we write, it is imperative that readers understand our background and current context. Both authors are two Black women who identify as scholarpractitioners committed to centering the voices and experiences of Black students along the African diaspora. Through a commitment to social justice, both authors aim to create research and expand the knowledge necessary to develop interventions that lead to equitable experiences for Black college students.

As we discuss further in forthcoming sections, participants are among populations who are underrepresented within study abroad programs (i.e. students of Color, first generation, or lowincome). Similarly, authors, both identifying as Black, and one who is first-generation, closely identify with the shared experiences of participants. Both authors have participated in study abroad programs, but only as members of doctoral programs. As such, we use this article to expand the knowledge of study abroad experiences of underrepresented students, particularly those who are Black.

Lastly, the leading author's participation as a graduate student in the discussed study abroad is important to note. The lead author was a doctoral student participant on this study abroad and served as a lead teacher during the internship. Serving as a graduate student on the study abroad provided the ability to work closely with the undergraduate student participants, while fully experiencing the various research, teaching and reading tasks allowed for entry to this particular project. As a part of the observer-participant experience, authors utilized pre-established relationships to select participants and set the context and framework for the study.

\section{Findings}

Participants' responses emphasized the importance of studying abroad, especially for Black students. Because of the intentionality of the structure of the program, the participants spent a significant amount of time considering their academic and career interests, and expanding their research abilities. Further, because the students only traveled with other Black students in a program sponsored and led by a Black studies department and Black faculty, they spent considerable time reflecting with peers on their understanding of their Black racial identity while studying within the Black diaspora. Three themes arose illustrating the experiences of all four participants in this study: (1) participants experienced an epistemological shift in the understanding of their academic interests and long-term goals, (2) had a better understanding of their racial identity, and (3) ended the study abroad experience with a stronger understanding of how to conduct undergraduate research.

\section{A greater sense of their academic interests and long-term goals}

The academic structure of the program entailed a part-time internship, academic lectures, and intensive language training. Undergraduate participants selected their internship focus between 
teaching at an international academy or serving as a research assistant. In both environments, students spent a significant amount of time facilitating their own learning and in the case of three of the participants, facilitating the learning of others. As a result, students were able to gain a stronger sense of where their academic interests lay. Brittany, a history major and an urban education minor, stated the experience "affected my perspective on education because I realize we take it for granted." Interning as a middle school creative writing teacher, focusing on Black or African authors, Brittany was able to connect her interest in history and education. During the interview she shared that she considered dropping her urban education minor but found that the internship reminded her how much she loved teaching, sharing "my internship really helped me realize that I want to be in the field working with students."

Not only were students able to understand their academic interests, they also found the experience to be liberating, resulting in an epistemological shift regarding how they were socialized to understand education. Ahmad (a film and journalism major) was particularly influenced by the opportunity to have academic experiences outside of the US. When asked his general feelings about the academic components of the trip, Ahmad responded,

Academically liberating. My entire academic career has been based within an American context... in the context of the United States... [it was] completely revitalizing to travel outside of that context to be able to learn and gain, and experience things, and gain knowledge that I otherwise would've never been able to conceptualize... allowed me to consider things that were plausible outside of my world.

Because participants' only exposure to formal education was from an American context, this study abroad trip allowed participants to experience another educational space and expand their understanding of education to include other contexts.

Prior to this program, two of the students had never studied abroad, so the opportunity to explore things outside of their US educational context was extremely important for them. Particularly due to the opportunities to engage intellectually with South African professors, graduate students, working class locals, and young adults, the undergraduate participants were able to pinpoint more clearly an academic trajectory that would lead to a more defined career path. Tonya said, "I noticed so many similarities, socially, educationally, governmentally...even talking about apartheid there was so many conversations about education, education, education...so now I think I'm considering going into education and governmental structure." As a result of the study abroad trip, Tonya, whose major is political science found that going into education would be a better way to positively impact the world.

As mentioned earlier, this particular study abroad experience provided participants with a greater sense of their academic interests. Since concluding the interviews for this study, all undergraduate participants have added the African American and African studies minor to their course of study.

\section{A better understanding of their racial identity}

Prior to departure on this trip the undergraduate participants all identified as Black in some capacity. However, the undergraduates demonstrated a stronger sense of who they were as Black 
individuals. Particularly Michelle (a comparative cultures and politics major), whose parents are from the Republic of Congo, found that the experience in South Africa helped her to become settled in who she was as a Black person with both African American and African identities,

South Africa really helped me to come to terms with the complexities of identity... before I would identify as African over Black...this need to assert this identity over that identity and going back and forth between the two...but being there and seeing Black Americans interact with Black Africans and this cultural exchange...this is your perception of us and this is our perception of you...these are the common experiences that we have, helped me to come to terms with the fact that identities are complex and you don't have to find one space or one box to fit yourself in.

While Michelle found that the trip allowed her to escape from the "box" of one racial identity, Brittany found that the trip helped her to create a box that includes her African heritage, but simultaneously acknowledges that her experiences and upbringing are not uniquely African.

I know for a long time I used to always say I'm African American when I would identify myself for some things...going to Africa made me realize that I'm not African, I'm Black...I'm not African American...I'm Black, our culture has retained a lot of culture and traditions and such from Africa...this trip helped me to realize that I'm Black, a part of the overarching identity... Black has it's own culture, though we may live in different parts of the world, we are still so much alike.

Particularly, because she was born and raised within the US, Brittany found that identifying as Black allowed her to connect with Black Africans in a way that identifying herself as African American could not.

Similar to in the US, South Africa delineates privilege based on race, which is socially constructed around the color of one's skin. Within this system, White South Africans have the most privilege and Black South Africans have the least privilege, while Coloreds and Indians reside in the middle space and are able to leverage privilege over Black South Africans. Tonya, a fair skinned Black woman, found this experience of being able to "opt out of being Black" within South Africa due to her skin tone prompted a sense of "duty" to her Blackness. She reflected,

The study abroad adventure has made me more Black! Over there I'm considered colored, which is considered privileged because I'm fair skinned... so in identifying with that privilege I feel that now I have even more of a responsibility in showing my Blackness and putting myself out there... I realize that I don't have to identify as black there, so now I have a duty... that I need to do more back home to work harder for the Black race.

Lastly, when asked how they identified themselves and what "Black" meant to them, all participants provided a definition that included Black as a political identity. So beyond just Black as a racial identity, participants found that identifying as Black connected them to Blacks along the African diaspora. Beyond just a racial identity, they seemed to find an intentionality and necessity to identifying as Black. Michelle shared,

Black is a political identification... you are Black because you have to assert an identity that allows you to protest the lack of resources that have been denied and excluded from given 
the history... biologically there's not reality of race, but there is a political reason to be Black... a political reason for people of color to assert a collective racial identity or cultural identity.

Ahmad furthered Michelle's point, stating "I find a certain pride in it [the term Black] ...I aspire to uncover an affinity towards this idea of Blackness in a society that claims to be deracialized." All participants shared that their understanding of Blackness broadly and their definition of their own Blackness, had been expanded by the study abroad trip to South Africa.

\section{A stronger understanding of how to conduct undergraduate research}

As a part of the trip, participants engaged in an individually chosen field research project. Topics ranged from "Women leaders in the African National Congress" to "The impact of South African media and propaganda on Black South Africans involvement in politics." Though seniors, participants had very little intentional research experience prior to the trip. As a result, participants were able to gain significant amounts of research experience, allowing them to have a better understanding of the usefulness of research and the mechanics behind conducting research.

Tonya, who had never conducted focus groups prior to South Africa, said "the focus group made me much more comfortable with research...listening to real people in group settings gets the conversation going because all of them differed in their views to move forward." She goes on to say "research can help you solve problems." Discussing her research project, Brittany mentioned it "helped me to realize that I can go to grad school and do well. I've done research now and I really can obtain some of the things that I want to do in the future." Through the research experience, Brittany developed greater confidence in her research abilities, which led to greater confidence in her post-graduate plans.

Beyond just the mechanics of research, the participants within this study found utility in African centered research methods. Michelle specifically stated "African centered methods of research ... the way that you're observing or researching the people, they are centered in the research..." When speaking about how the research may be different than Western ways of conducting research, Michelle shared,

not only are you trying to understand, but also to produce any type of knowledge that is most beneficial to them, whereas in other research I would do in the past, I would have a topic you know read about it, write about it, but would have no real understanding of the consequences of this research or the consequences of me entering this environment, my positionality in all of this... especially in AAAS [African and African American Studies], being in that space and learning this type of research has helped me to understand the impact of my research.

Regarding the impact of research, Ahmad adds “.... you have to be aware of the biases you carry, mentally where you are, your positionality... also questioning the way knowledge is produced... acknowledging the ways of learning... one way may not be the best way. Not valuing a way of learning over another." Michelle later says, "you don't just go in and come out, you really are making an impact and it's important that you understand yourself and the knowledge that's always been produced there...there is an interchange and what is that and how will it be useful?" Participants were able to consider different ways of conducting research, but also consider the 
impact of research methods in non-US contexts. Further, this particular study abroad helped participants to see the possibility for doing research that aligns more with their sense of self and conducting research within the Black diaspora as members of the Black community.

\section{Discussion}

Utilizing an Afrocentric paradigm, the purpose of the current study was to explore how a fourweek study abroad experience to South Africa influenced Black undergraduate students (Mazama, 2003). By centering the experiences of students identifying within the African diaspora in study abroad, researchers were able to understand more holistically the influence of the trip on participants. Our findings highlighted the ways participation in an intentionally designed study abroad program to South Africa influenced participants' 1) long-term career and academic goals, 2) understanding of their own racial identity, and 3) understanding of research. As Tolliver (2000) suggested, and as reiterated in our findings, Black students greatly benefited from participation in SARP, both racially and academically. Further, participants were able to explore their heritage (Brux \& Fry, 2010) in order to learn new things, but more importantly to un-learn the stereotypes and misinformation regarding Africa and African heritage, which is often taught in schools. The findings in the current study confirm Black undergraduate students are positively influenced, culturally and academically, by study abroad experiences to the African continent. Therefore, more research on their experiences is greatly needed.

Consistent with Dawson (2000), and Penn and Tanner (2009), the current study found Black participants who traveled to Africa expressed gratitude for the homegoing experience. Upon returning, they felt more equipped to answer questions about who they were and where they originated. Also consistent with Penn and Tanner (2009), and Tolliver (2000), we found Black participants who studied abroad with other Black students gained a deeper self-understanding from a shared historical lens allowing them to experience their surroundings in a more meaningful way.

Centering Black experiences and participants self-identifying as Black from the African diaspora, are essential elements of this study abroad experience. As such, Black students had the opportunity to discuss and experience the complexities of race and racial identity. Students were able to share their experiences in a comfortable environment with one another and with whom they interacted in South Africa because all participants in this study abroad self-identified as Black. As a result of complex conversations around race, heritage, and the African diaspora, coupled with the unique Sangoma Ceremony experience, students gained a better understanding of themselves and a stronger sense of ancestral connections, which is consistent with Brux and Fry (2010), Penn and Tanner (2009), Tolliver (2000). Discussions of race, heritage and the African diaspora positively influenced the participants' racial identity, particularly as a Black person, and their connection to other Black experiences along the diaspora.

After participating on SARP, students found connections between their racial identity and the sociocultural aspects of African diasporic education in more complex and intentional ways. For example, participants who were not already minoring in African American and African studies later added the minor upon returning, which demonstrates an expanded connection to the Africana studies broadly and a felt connection or interest to the African diaspora. The various points of engagement in South Africa also made students aware of some African cultural traditions that have 
been retained despite the assumed disconnect that continues in contemporary US society. African retention, or US practices that were retained through slavery and are still practiced today. In totality, student participants have a new understanding of Africa broadly, and more specifically South Africa. This new understanding and sense of connection helps to combat the misunderstanding that Dawson (2000) argues many Black students have regarding their relationship with Africa.

Participants in this study each engaged in a research project as a part of the study abroad experience. Prior to this study abroad, these students had little to no experience with the mechanics of the research as a process. As a result, students now have an understanding of how to conduct a research project, how it can impact individuals and communities, and how researchers must be careful about who, what, how, and why they conduct research. Additionally, because participants learned how to conduct research from this study abroad experience, they now have an interest in graduate school and believe graduate school is attainable.

Consistent with the Afrocentric paradigm, student participants were able to engage in their own creation of knowledge (Mazama, 2003), both through their individualized research projects and through the collaborative learning, which took place while on SARP. Further, the intentionality in the structure of SARP connects broadly to the Afrocentric paradigm, which allowed for a holistic and meaning-making experience for participants. While in South Africa, SARP participants were able to make meaning around their racial identities, academic futures, and sense of self, all of which are consistent with Afrocentricity (Mazama, 2003).

Afrocentricity centers the experiences of Blacks along the African diaspora in a way that intertwines cultural, spiritual, and experiential knowledge. SARP was intentional in its program design to provide spaces for students to engage culturally, spiritually, and experientially within the various cultural excursions, opportunities to engage with community members, and intensive language courses. More than just program design, SARP was also intentional with readings, research opportunities, and participant internships, ensuring that participants were able to further their knowledge of self and South Africa culturally, spiritually, and experientially. As a result of participation, and consistent with the purpose of Afrocentricity (Mazama, 2003), participants found the experience to be liberating, uplifting, and necessary. Illuminating the necessity of centering Black experiences, particularly within Black spaces, SARP created unique opportunities for learning and un-learning for participants. When done intentionally, study abroad trips are ideal spaces for these unique opportunities and can to lead to liberating education for Blacks who have been historically mis-educated (see Woodson, 1933).

\section{Implications for future research and practice}

Centering the Black experience within Study Abroad is necessary to further expand study abroad participation within higher education. As a result of the current study, we present important research and practice implications, which should be considered by student abroad researchers, and higher education practitioners and administrators. What follows is a discussion of recommendations generated from the findings in the current study. 


\section{Implications for practice}

There are three broad implications for practice around study abroad in higher education. The first implication is centered around intentionality and program development. Programs like SARP contribute to the field of study abroad by being intentional in design to ensure students are culturally and academically engaged with the country within which they are studying. Furthermore, when focused on group make-up, programs like SARP, can intentionally center racial identity development and heritage seeking.

More programs need to examine the importance of location, group make-up, and learning during the experience. Heritage seeking for students of color studying abroad may result in a sense of homegoing, acceptance, and empowerment (Tsantir \& Titus, 2006). As demonstrated with the Black students in our study and supported by Dawson (2000) and Penn and Tanner (2009), these heritage experiences allowed them to feel more equipped to respond to questions about who they are and where they are from. As such, study abroad programs, particularly targeting Black students and visiting African countries, should be intentional in their design.

Not all institutions have the ability to develop identity-specific programs and may have programs in varying parts of the world. However, when intentionally and thoughtfully designed, programs can still make heritage seeking and racial identity development a priority for student participants regardless of racial or ethnic background.

The second broad implication centers the connection between studying abroad and collaborative research. Intentionally engaging with collaborative research, and working with South African professors and teachers, while studying the cultural history of the country, provided a space for rich data collection and thought provoking analysis for participants. This differs greatly from common programs to African countries which center visiting safaris and helping "poor African children" as opposed to developing strong research skills. Thus, study abroad programs to African countries and across the globe, should be more intentional in including research based projects and collaborative research opportunities.

Lastly, the influence of this study abroad trip on students' academic trajectory is an important point to consider for future trip leaders and study abroad staff. Since increasing the underrepresentation of Black students in study abroad is a priority, a potential strategy for recruiting underrepresented students may be showing them the academic benefit of study abroad participation. For instance, if students see the connection between studying abroad and completing requirements for an academic major or minor, they may be more likely to participate.

\section{Research implications and recommendations}

There are four broad implications and recommendations for research. The first recommendation for research focuses on exploring reasons Black students are underrepresented in study abroad. Higher education and specifically education abroad program practitioners need to understand more closely why Black students are underrepresented in study abroad (M'Balia, 2013; Sweeney, 2013; Twombly et al., 2012). Knowing why Black students do not participate can aid practitioners in developing systems to increase study abroad participation. Thus, future research must be conducted to understand the barriers involved in keeping Black students away from study 
abroad programs. More particularly, future research must be conducted to understand barriers keeping Black students away from studying in African countries.

The second recommendation for research is to gain a greater understanding around Black student experiences while studying abroad. Higher education practitioners and scholars need to be more engaged in creating spaces for sharing these experiences, not just for the field, but also for recruitment purposes. Sharing stories and understanding the experiences of Black students who study abroad and how it benefited them (Brux \& Fry, 2010) is vital. Not only do more stories add to the limited research, but may also respond to the issues of underrepresentation of Black students in study abroad.

Thirdly, practitioners need to understand the individualized experiences across varying social positionalities. For instance, study abroad research on Black students often groups together the experiences of those who identify as women and men (Winkle-Wagner, 2009). Research on Black study abroad participants collectively is not enough. Researchers must be intentional about exploring and presenting lived experiences from the unique and varying perspectives of participant social positionalities.

Lastly, scholars writing about their study abroad experiences to specific countries in Africa need to note the context for the region(s) they are visiting. Much of the literature regarding study abroad trips to Africa lacked this context in their research, leaving out the diversity of regions, which is essential to understanding the experience accurately and holistically.

In summation, study abroad practitioners and researchers must be intentional in data collection and program implementation, while also being thoughtful about the ways we often conduct research around studying abroad to African countries and for Black students. According to our findings, programs like SARP create opportunities for Black students to view themselves positively within Black spaces both culturally and academically. The presented implications for future research and practice, can serve as a starting place for study abroad researchers and practitioners.

\section{Conclusion}

A common problem in study abroad is the underrepresentation of Black students and there is a lack of their experiences in study abroad research. Further, research on the experiences and positive outcomes of study abroad for Black college students is required to draw concrete conclusions. As such, this research examined what Black students learned about themselves and how their career trajectory was influenced by this study abroad trip. Findings suggest positive outcomes, though the participant number was small. For this reason, it is imperative that research is conducted to better understand what hinders Black students from studying abroad. Exploring these topics through research and practical programming could lead to positive outcomes and increased participation for Black students.

\section{References}

Asante, M. K. (1987). The afrocentric idea. Philadelphia, PA: Temple University Press.

Brown, L. M. (2002). Going global; traditionally, the percentage of African American students who studied abroad has been low; however, university officials are looking into ways to increase those numbers. Black Issues in Higher Education, 19(6), 28-31. 
Brownell, J. E., \& Swaner, L. E. (2009). High-impact practices: Applying the learning outcomes literature to the development of successful campus programs. Peer Review, 11, 26-30.

Brux, J. M., \& Fry, B. (2010). Multicultural students in study abroad: Their interests, their issues, and their constraints. Journal of Studies in International Education, 14(5), 508-527.

Charmaz, K. (2006). Constructing grounded theory: A practical guide through qualitative analysis. London, UK: SAGE.

Chase, S. E. (2005). Narrative Inquiry: Multiple Lenses, Approaches, Voices, in N. K. Denzin and Y. S. Lincoln (eds) Handbook of Qualitative Research, 3rd edn, 651-79. Thousand Oaks, CA: Sage.

Chase, S. (2011). Narrative inquiry: Still a field in the making, in N. Denzin \& Y. Lincoln (eds.), The SAGE handbook of qualitative research (4th ed.). Thousand Oaks, CA: Sage.

Cheppel, A. (2012). A phenomenological study of undergraduate African American college students' decision to participate in study abroad (Doctoral dissertation). Retrieved from ProQuest, UMI Dissertations Publishing (3531377).

Creswell, J. W. (2007). Qualitative inquiry and research design: Choosing among five approaches (2nd ed.) Thousand Oaks, CA: SAGE.

Creswell, J. W. \& Miller, D. L. (2000). Determining validity in qualitative inquiry. Theory into Practice, 39(3), 124-131.

Dawson, N. J. (2000). Study Abroad and African American College Students at Southern Illinois University at Carbondale. African Issues, 124-129.

Day-Vines, N. L. (1998). Study abroad: An investigation of the impact of African diasporic travel on the psychosocial development of African American college sojourners (Doctoral dissertation). Retrieved from ProQuest, UMI Dissertations Publishing.

Day-Vines, N., Barker, J. M., \& Exhum, H. A. (1998). Impact of diasporic travel on ethnic identity development of African American college students. College Student Journal, 32(3), 463-471.

Esterberg, K. G. (2002). Qualitative methods in social science research. Boston, MA: McGrawHill.

Gasman, M., Baez, B., \& Turner, C. S. V. (2008). Understanding minority-serving institutions. Albany, NY: State University of New York Press.

Gearhart, R. (2005). Taking American race relations on the road ... to Africa. African Studies Quarterly, 8(2), 70.

Glesne, C., \& Peshkin, A. (2011). Becoming qualitative researchers: An introduction. White Plains, NY: Longman.

Hammersley, M. (2008). Questioning qualitative inquiry: Critical essays. Los Angeles, CA: Sage.

hooks, b. (1984). Feminist theory from margin to center. Boston, MA: South End Press.

Institute of International Education (IIE). (2013). Open Doors Report on International Educational Exchange. Retrieved from http://www.iie.org/opendoors

Jackson, M. J. (2006). Traveling shoes: Study abroad experiences of African American students participating in California State University international programs (Doctoral dissertation). Retrieved from ProQuest, UMI Dissertations Publishing.

Kasravi, J. (2009). Factors influencing the decision to study abroad for students of color: Moving beyond the barriers (Doctoral dissertation). Retrieved from ProQuest, UMI Dissertations Publishing.

Kuh, G. D. (2008). High-Impact Educational Practices. Washington, DC: American Association for Colleges \& Universities.

Kuh, G. D., Kinzie, J., Schuh, J. H., \& Whitt, E. J. (2010). Student success in college: Creating conditions that matter. San Francisco, CA: Jossey-Boss.

Landau, J., \& Moore, D. C. (2001). Towards reconciliation in the motherland: Race, class, nationality, gender, and the complexities of American student presence at the University of Ghana, Legon. Frontiers: The Interdisciplinary Journal of Study Abroad, 7, 25-59.

Lincoln, Y. S., \& Guba, E. G. (1985). Naturalistic inquiry (Vol. 75). Los Angeles, CA: Sage.

Mazama, A. (2003). The Afrocentric Paradigm. Trenton, NJ: Africa World Press, Inc.

M'Balia, T. (2013). The problematization of racial/ethnic minority student participation in US study abroad. Applied Linguistics Review, 4(2), 365-390. 
Miles, M. B., \& Huberman, A. M. (1994). Qualitative data analysis: An expanded sourcebook. Thousand Oaks, CA: SAGE.

NAFSA: Association of International Educators. (2003). Securing America's Future: Global Education for a Global Age. Retrieved from http://www.nafsa.org/uploadedFiles/NAFSA_Home/ Resource_Library_Assets/Public_Policy/securing_america_s_future.pdf

NAFSA: Association of International Educators. (2015). Trends in U.S. Study Abroad. Retrieved from http://www.nafsa.org/Explore_International_Education/Advocacy_ and_Public_Policy/Study_Abroad/Trends_in_U_S_Study_Abroad/

National Survey of Student Engagement (NSSE). (2007). Experiences that matter: Enhancing student learning and success. Bloomington, IN: Indiana University Center for Postsecondary Research. Retrieved from: http://nsse.iub.edu/nsse_2007_annual_report/

Nolan, R. W. (2009). Turning our back on the world: Study abroad and the purpose of US higher education. In R. Lewin (ed.) The handbook of practice and research in study abroad: Higher education and the quest for global citizenship, 266-281. New York, NY: Routledge.

Patton, M. Q. (1990). Qualitative evaluation and research methods. Thousand Oaks, CA: SAGE.

Patton, M. Q. (2002). Qualitative interviewing. Qualitative research and evaluation methods, 3, 344-347.

Penn, E. B., \& Tanner, J. (2009). Black students and international education: An assessment. Journal of Black Studies, 40(2), 266-282.

Polkinghorne, D. E. (2007). Validity issues in narrative research. Qualitative inquiry, 13(4), 471-486.

Reviere, R. (2001). Toward an Afrocentric Research Methodology. Journal of Black Studies, 31(6), 709728.

Sweeney, K. (2013). Inclusive Excellence and Underrepresentation of Students of Color in Study Abroad. Frontiers: The Interdisciplinary Journal of Study Abroad, 23, 1-21.

Tolliver, D. E. (2000). Study abroad in Africa: Learning about race, racism, and the racial legacy of America. African Issues, 28(1/2), 112-116.

Tsantir, S. B. \& Titus, B. J. (2006). Heritage seeking and education abroad: A case study. IIE Networker Magazine. Retrieved from http://www.nxtbook.com/nxtbooks/naylor/IIEB0206/index.php?started $=27 \# / 26$.

Twombly, S. B., Salisbury, M. H., Tumanut, S. D., \& Klute, P. (2012). Study Abroad in a New Global Century: Renewing the promise, refining the purpose, ASHE higher education report. Hoboken, NJ: John Wiley \& Sons.

Walker, S., Bukenya, J. O., \& Thomas, T. (2011). Examining Students' Perceptions of Globalization and Study Abroad Programs at HBCUs. US-China Education Review, 8(6), 77-88.

Willis, T. Y. (2012). Rare but there: An intersectional exploration of the experiences and outcomes of Black women who studied abroad through community college programs. (Unpublished doctoral dissertation). California State University, Long Beach, CA.

Winkle-Wagner, R. (2009). The unchosen me: Race, gender, and identity among black women in college. Baltimore, MD: Johns Hopkins University Press.

Woodson, C. G. (1933). The mis-education of the Negro. Washington, DC: Associated Publishers.

Yin, R. K. (2008). Case study research. Los Angeles, CA: SAGE. 